\title{
Unwarranted Complication in Posterior Dynamic Stabilization of the Spine: Review of Literature and Description of a Case Encountered by the Author
}

\author{
Ramani PS, Nitin Jagdhane* and Arjun Dhar \\ Department of Neurosurgery, Lilavati hospital and research center, India
}

Submission: March 10, 2017; Published: May 04, 2017

*Corresponding author: Nitin Jagdhane, Department of Neurosurgery, Lilavati hospital and research center, India, Email: drjagdhane@gmail.com

\begin{abstract}
PLIF is a common procedure used to stabilize the spine. It is rigid and results in ASD (Adjacent segment degeneration). In recent times, posterior dynamic stabilization (PDS) has become popular. The implant is inserted either directly or by percutaneous method in the interspinous or the inter-laminar space. It is then fixed to the spinous processes. Superion and CoFlex are FDA approved and popular devices in the market. During the operative procedure, at times one of the spinous processes breaks leaving the surgeons perplex about how to proceed. In our experience with 300 CoFlex PDS, we encountered one case where one of the spinous processes (L4) broke. The senior author is familiar with intra-spinous process drilling. This technique was utilized to thread through the drill holes a Vicryl, and tie the two broken pieces of spinous process together successfully. The surgical procedure was concluded by the insertion of the CoFlex PDS. In the literature, we found a few articles mentioning on the breakage. In all these cases, the procedure was abandoned. Two years have passed and the patient continues to remain symptom free without any displacement of the implant.
\end{abstract}

Keywords: PDS; Breakage of spinous process; Reconstruction; Stabilization

Abbreviations: PLIF: Posterior Lumbar Interbody Fusion; PDS: Posterior Dynamic Stabilization; ASD: Adjacent Segment Degeneration; FDA: Federal Drugs Administration

\section{Introduction}

Posterior lumbar interbody fusion (PLIF) is a very common surgical procedure on the spine practiced all over the world [1]. It is a rigid stabilization and speaking biomechanically, not a convincing procedure as it stopped motion in one or two spinal segments. Adjacent segment disease (ASD) became an important issue and surgeons were also worried about the complications arising from the implants [2-4].

\section{Posterior Dynamic Stabilization}

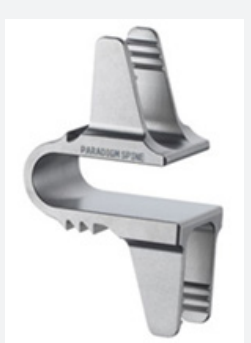

Figure 1: CoFlex inter-laminar dynamic PDS implant.

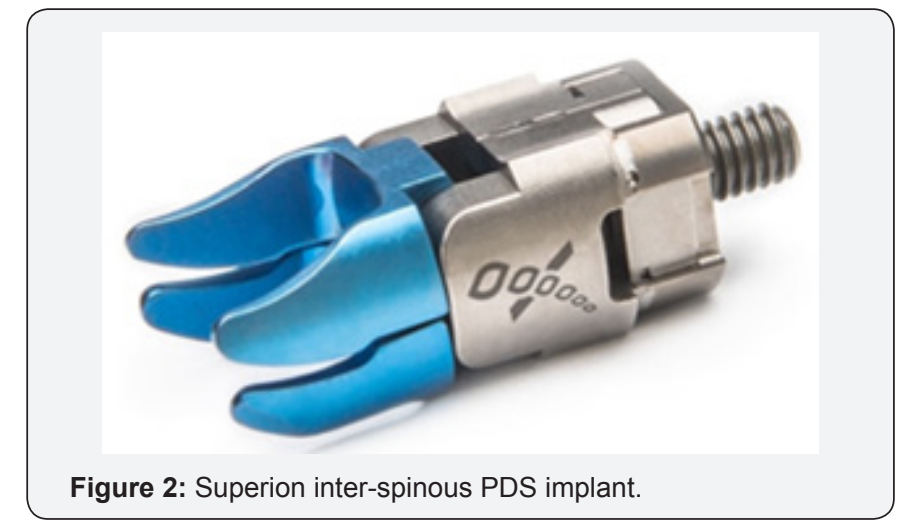

In recent times, the trend changed towards dynamic stabilization and PDS (Posterior dynamic stabilization) became popular. Of the several varieties of procedures, inter-spinous or inter-laminar device remained popular. Number of implants came in the market, but, as of today, only two implants are FDA approved and have stood the test of time with long term follow up i.e. CoFlex [5] (Figure 1) and Superion [6] (Figure 2). 


\section{Breakage of Spinous Process}

In PDS, the adjacent spinous processes have to be exposed. During the procedure, inadvertently, one of the spinous processes breaks and puts the surgeon in a dilemma as to 'what to do next?'

\section{Literature Review}

There have been a few case reports reported in the literature.

A. L Zang et al. [7] in their series of 133 patients have reported 3 cases of intraoperative fracture of spinous process and 2 cases of fracture post operatively. All cases of intraoperative fracture and one case of postoperative fracture were managed by alternate surgical procedure of pedicle screw fixation whereas one postoperative fracture was managed conservatively [8].

B. Xu et al. [9] in their analysis of complications in interlaminar device CoFlex, studied 131 patients and reported one patient where spinous process was broken. The fracture of spinous process was seen after 1 week of surgery on CT scan. Patient was conservatively managed and showed bone healing on CT scan done 1 year later [9].

C. In our series of 300 CoFlex devices, we encountered one patient where one of the spinous process was fractured while excising the inter-spinous ligament between L4 and L5, spinous process of $\mathrm{L} 4$ broke in 2 pieces with posterior half hanging with the support of L3-L4 supra-spinous ligament (Figire 3a). This was a setback for the planned surgical procedure. However, the senior surgeon thought over the issue and decided to reconstruct the spinous process. Senior surgeon is conversant with the procedure of threading intra-laminar wire with a fine drill and this technique was utilized to produce an intralaminar drill hole in the anterior and posterior broken spinous processes (Figure 3b \& 3c). The holes were threaded with No 1 Vicryl and approximated together by tying the Vicryl thereby reconstructing the spinous process (Figure $3 \mathrm{~d} \& 3 \mathrm{e}$ ).

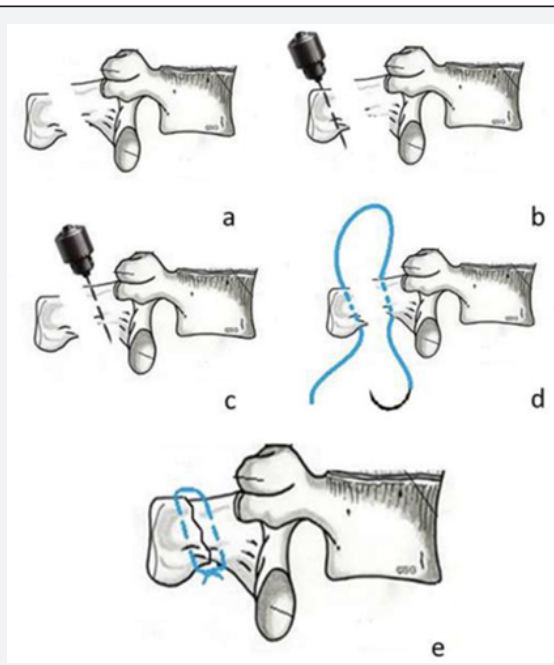

Figure 3: (a) Broken spinous process; (b and c) Intra-laminar drilling of the two ends; ( $d$ and e) Threading with vicryl and tying the two ends together.
Admittedly this was a relatively weaker assembly albeit temporarily, but when inter-laminar device was fixed in position, the central pillar was very stable as it functioned more with the stability of the other spinous processes. The assembly was very stable. Post operatively, patient was very satisfied and for the first time after 10 months, he was able to walk freely in the hospital corridor without support and without LS belt. Two years have passed and he has not complained of pain or any other incidence.

\section{Discussion}

In the literature, there are number of papers discussing complications of posterior dynamic devices but we could not find any paper where such complication was managed in the manner we have described. On personal communication with various workers internationally and on reviewing the literature, we found that breakage of spinous process during surgical procedure in not uncommon [7-9]. However, all the time when there was intra operative breakage of spinous process, the procedure was abandoned. In this case, by using the technique described above, we have managed to treat the patient successfully with the surgical strategy as planned before the operation.

FDA guidelines for the product [10] state that data has demonstrated that spinous process fractures can occur during surgery. Potential predictors for spinous process fractures include, over-decompression during surgery leading to instability in the spine (which was not in our case), or resection of the spinous process to less than or equal to $14 \mathrm{~mm}$ (in this case, we had not even touched the spinous process.) The spinous process in our case was more than $23 \mathrm{~mm}$ in height and there was no clinical evidence of osteoporosis in this patient (Figure 4).

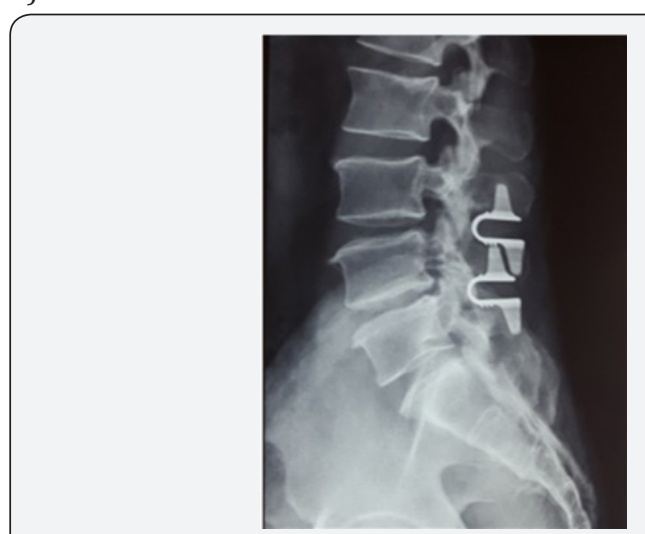

Figure 4: Postoperative X-ray with broken L5 spinous process.

\section{Conclusion}

Unwarranted complication in a surgical procedure can put the surgeon in a quandary; however, without losing patience the surgeon can utilize his expertise and manage the complication in a very satisfactory way. 


\section{References}

1. Turner JA, Ersek M, Herron L, Deyo R (1992) Surgery for lumbar spinal stenosis: attempted meta-analysis of the literature. Spine 17(1): 1-8.

2. Bridwell KH, Sedgewick TA, O’Brien MF, Lenke LG, Baldus C (1993) The role of fusion and instrumentation in the treatment of degenerative spondylolisthesis with spinal stenosis. J Spinal Disord 6(6): 461-472.

3. Boos N, Webb JK (1997) Pedicle screw fixation in spinal disorders: a European view. Eur Spine J 6(1): 2-18.

4. Booth KC, Bridwell KH, Eisenberg BA, Baldus CR, Lenke LG (1999) Minimum 5-year results of degenerative spondylolisthesis treated with decompression and instrumented posterior fusion. Spine 24(16): 1721-1727.

5. Bae HW, Lauryssen C, Maislin G, Leary S, Musacchio MJ (2015) Therapeutic sustainability and durability of coflexinterlaminar stabilization after decompression for lumbar spinal stenosis: a four year assessment. Int J Spine Surg 9: 15.
6. Patel VV, Nunley PD, Whang PG, Haley TR, Bradley WD, et al. (2015) Superion(®) InterSpinous Spacer for treatment of moderate degenerative lumbar spinal stenosis: durable three-year results of a randomized controlled trial. J Pain Res 8: 657-662.

7. Zang L, Hai Y, Su QJ, Lu SB, Zhang CS, et al. (2012) Device implanted complications of Coflex interspinous dynamic stabilization. Zhonghua Wai Ke Za Zhi 50(9): 782-787.

8. Zang L, Du P, Hai Y, Su QJ, Lu SB, et al. (2013) Device related complications of the Coflexinterspinous process implant for the lumbar spine. Chin Med J (Engl) 126(13): 2517-2522.

9. Xu C, Ni WF, Tian NF, Hu XQ, Li F, et al. (2013) Complications in degenerative lumbar disease treated with a dynamic interspinous spacer (Coflex). In Orthop 37(11): 2199-2204.

10. PMA P110008: FDA Summary of Safety and Effectiveness Data.

\section{Your next submission with Juniper Publishers will reach you the below assets}

- Quality Editorial service

- Swift Peer Review

- Reprints availability

- E-prints Service

- Manuscript Podcast for convenient understanding

- Global attainment for your research

- Manuscript accessibility in different formats

( Pdf, E-pub, Full Text, Audio)

- Unceasing customer service

Track the below URL for one-step submission https://juniperpublishers.com/online-submission.php 